\title{
Chapter 15 \\ Continuity and Change in Older Adults' Out-of-Home Mobility Over Ten Years: A Qualitative-Quantitative Approach
}

\author{
Heidrun Mollenkopf, Annette Hieber, and Hans-Werner Wahl
}

Both the ability and the opportunity to move about constitute essential requisites to older adults' independent living and societal participation. The ability-that is the fundamental physical capacity-to move is a basic human need and essential to personal health (e.g., Heikkinen et al., 1992; U.S. Department of Transportation, 2003). In that sense, declining mobility has been understood predominantly as a physical health and geriatric issue. For decades, a broad range of research has been conducted to understand, among other things, the increasing decline in mobility performance, including decrements in sensory abilities and sensorimotor integration, loss of motor control and voluntary strength, slowing motor action and speed of processing. shrinking range of motion and flexibility, and decreasing ability to stabilize posture (e.g., Fozard, 2003; Fozard \& Gordon-Salant, 2001; Ketcham \& Stelmach, 2001; O’Neill \& Dobbs, 2004; Owsley, 2004; Spirduso, 1995).

The ability to move about - and by extension to travel—is required to navigate from point $\mathrm{A}$ to point $\mathrm{B}$, to seek out places of subjective interest or that are essential to meeting daily material needs, to participate in cultural and recreational activities, and to maintain social relations, familiar habits, and life styles - in short, to live an autonomous life for as long as one's mental and physical capacities permit one to participate actively in society (Schaie, 2003). At the same time, age-related changes such as physical, cognitive, and/or sensory impairments and social losses may limit older adults' possibilities of ambulating and venturing out.

A multitude of studies in transportation research have provided rich statistical data on older adults' actual travel behavior, usually defined as a movement in time

H. Mollenkopf • A. Hieber

German Center for Research on Aging, Heidelberg University, Heidelberg, Germany

H.-W. Wahl (ه)

Institute of Psychology, Heidelberg University, Heidelberg, Germany

e-mail: hans-werner.wahl@psychologie.uni-heidelberg.de 
and space, measured in terms of trips or journeys and reported in standardized diary forms (e.g., Centre d'études sur les réseaux, les transports, l'urbanisme et les constructions publiques [CERTU], 2001; Clarke \& Sawyers, 2004; European Conference of Ministers of Transport [ECMT], 2000; Organisation for Economic Co-operation and Development, 2001; Rosenbloom, 2001; Schaie \& Pietrucha, 2000; Transportation Research Board [TRB], 1988). It is true that findings differ depending on national peculiarities, but general tendencies and structures correspond in some salient aspects: In general, travel of older adults has clearly increased for about two decades. However, the older individuals are, the less they tend to travel, mainly due to declining health and sensory impairments. Older individuals with a driver's license and access to a private automobile travel more than those with no car at their disposal. Because the current generation of older women has less education, a lower income, and less likelihood of having a driver's license than men of the same age, it is not surprising that they use public transportation more than men do, whereas older men use the car more often, take more trips, and travel more miles than older women (see e.g., Banister \& Bowling, 2004; ECMT, 2000; Marottoli et al., 1997; Mollenkopf et al., 2002; Owsley, 2002; Rosenbloom, 2004).

Despite the abundant information available from these research strands, the functional approaches to mobility often neglect the key mobility concerns of older adults (Alsnih \& Hensher, 2003; Banister \& Bowling, 2004; Gabriel \& Bowling, 2004; Hildebrand, 2003; Mollenkopf, Marcellini, Ruoppila, \& Tacken, 2004a; Schlag \& Schade, 2007; Siren \& Hakamies-Blomqvist, 2004). The meaning individuals attribute to mobility and their experiences when venturing out are only scarcely assessed. However, mobility can be for its own sake and not just as a derived demand (Mokhtarian, 2005). Case studies conducted in four European cities showed that mobility means much more to older adults than the mere covering of distance (Mollenkopf et al., 2004a). In this context the attraction or deterrence of the natural, social, and built environment can play a crucial role (Banister \& Bowling, 2004; Holland et al., 2005). Motivational, cognitive, or personality aspects also play an important role in their decisions to go out. Moreover, in modern society, mobility is associated with highly appreciated goals like freedom, autonomy, and flexibility (Cobb \& Coughlin, 2004; Handy, Weston, \& Mokhtarian, 2005; Lash \& Urry, 1994; Mollenkopf, Marcellini, Ruoppila, Széman, \& Tacken, 2005; Rammler, 2001). Older adults are members of current societies and therefore are affected by these societies' Zeitgeist, values, and expectations.

Only in recent years has the focus shifted to more subjective and motivational aspects of travel and driving behavior. A series of recent studies showed that older adults' ability to move about and to pursue outdoor leisure activities contributes significantly to their autonomy, social participation, and subjective quality of life (Banister \& Bowling, 2004; Cvitkovich \& Wister, 2001; Fernández-Ballesteros, Zamarrón, \& Ruíz, 2001; Marottoli et al., 1997; Mollenkopf et al., 2004a; Mollenkopf, Baas, Kaspar, Oswald, \& Wahl, 2006; Owsley, 2002; Pochet, 2003). Satisfaction with one's ability to get around, to pursue leisure activities and to travel 
were significant determinants of quality of life in a study comparing the impact of subjective appraisal of different life domains on satisfaction with life in general (Mollenkopf et al., 2006). In a study focusing on elderly people's own definitions of quality of life, Farquhar (1995) found that the ability to go out more was cited as improving quality of life, whereas being housebound detracted from quality of life. Similar findings were reported by Coughlin (2001) with respect to the significance of transportation, albeit mostly related to being able to drive a car. Banister and Bowling (2004) found that a sense of optimism and positive expectations of life constitute a main building block for the transport dimension of older adults' perceptions of quality of life. Psychological variables such as control beliefs and the individual importance attributed to being out also played a role in characterizing groups of older adults who differed in their out-of-home mobility patterns (Mollenkopf et al., 2004b).

Altogether, these findings offer some evidence that functional necessities, on the one hand, and modern values and individual needs on the other, strongly complement one other. In this chapter we wish to further pursue a comprehensive understanding of older adults' out-of-home mobility by taking up and integrating the diverging concepts of mobility in an environmental gerontology perspective (Wahl, Mollenkopf, Oswald, \& Claus, 2007; Wahl \& Oswald, 2010). Proceeding from this approach, which asserts that an individual's well-being is influenced by how well environmental resources match personal needs, we propose that mobility and related appraisals are determined by personal (health-related and psychological) and socioeconomic factors as well as by environmental (structural) conditions and features of the person-environment interaction. Findings of the European MOBILATE project largely confirmed this fundamental view of mobility in cross-sectional as well as longitudinal analyses over the 5-year observation period from 1995 to 2000 (Mollenkopf et al., 2005).

This chapter presents data based on an extended observational period up to 2005, for a total observation time of 10 years. We assume that during that time the men and women who had participated in the 1995 study might have experienced agerelated health impairments, critical social life events (e.g., death of a spouse), and changes in their local environments, all of which can seriously jeopardize the outdoor mobility of the older individual.

The goals of our work are threefold. First, we describe 10-year trajectories in terms of stability and change of various key qualifiers (e.g., satisfaction) of out-ofhome mobility such as out-of-home mobility in general, public transportation, outof-home leisure activities, and travel. Second, we link and undergird these trajectories with the explicit consideration of meaning imposed on mobility, perceived changes in mobility and perceived reasons for change, as well as satisfaction with life in general. Third, we will explore interindividual differences in stability and change. We strongly believe that only a mix of methods, in other words, qualitative and quantitative, allows these goals to be addressed in a comprehensive manner. 


\section{Method}

\section{Study Design}

This study started with an initial inquiry on older adults' out-of-home mobility carried out in four European cities in 1995 (Mollenkopf et al. 2004a). The German parts of the investigation - on which the present study is based-were carried out in the cities of Mannheim (western Germany) and Chemnitz (eastern Germany). Both of them are middle-sized industrial cities with diversified settlement structures and public transportation (tram and bus lines) as well as rail connections and national roads. The quantitative part of the study included $N=804$ persons aged 55 years or older, which resulted from a randomly drawn sample of addresses from the population registers of the Municipality Registration Offices of Chemnitz and Mannheim. Thirty-five of the participants were selected for additional in-depth interviews because they showed a particularly low or high degree of mobility. Five years later (2000), 271 respondents from the original sample could be reassessed in an initial follow-up as part of the project entitled "Mobilate: Enhancing Outdoor Mobility in Later Life" funded by the European Commission in the Fifth Framework Programme (Programme Area no. 6.3, Project QLRT-1999-02236). The comparative findings of this international and interdisciplinary project, including data from Finland, Germany, Hungary, Italy, and the Netherlands, have been published elsewhere (e.g., Mollenkopf et al., 2003, 2005, 2006; Mollenkopf, Ruoppila, \& Marcellini, 2007). Another 5 years later (2005), a third assessment took place in the German cities and resulted in $N=82$ participants, or approximately $30 \%$ from the first follow-up and $11 \%$ from the original sample. Hence, the present study covers these participants over a 10 -year period.

Well-trained interviewers from the USUMA research institute (Berlin) conducted the German interviews in 1995 and 2000. The 2005 Chemnitz interviews were also conducted by USUMA interviewers, and the interviews in Mannheim were conducted by the project staff.

\section{Sample Description and Drop-Out}

The original German sample of $N=804$ participants was disproportionately stratified by age and sex, resulting in almost equal subcategories of men and women (50 $\%$ each) and two age groups (51.2\% respondents aged 55-74 years and $48.8 \%$ aged 75 years or older). The composition of the age groups changed from the first assessment in 1995 to the second in 2000 (61.3\% aged 55-74 years and 38.7\% aged 75 years or older) and even more dramatically from the second to the third assessment in 2005 (84.2\% aged 55-74 years and $15.8 \%$ aged 75 years or older). By shifting the age group limit by 10 years and drawing on the participants' actual age in 2005 , we again obtained two groups of the same size (50\% each of respondents 65-74 years old and 75 years old or older). 
The reasons for dropping out of the sample were documented in standardized protocols. Because of the long period of time, the most frequent reasons were the death of the former participants or a deterioration in their health (almost $20 \%$ each). Other dropouts were due to refusals to continue participation and failure to locate or gain access to them. Logistic regression analysis based on data from the 2000 study indicated that age $\left(O R=.94^{*}\right),{ }^{1}$ education $\left(O R=1.59^{*}\right)$, and the number of transport modes used in $2000(O R=1.27 * *)$ seemed to influence participation in 2005 . Probability of participation increased with younger age, higher education, and greater variety of transport modes used. The level of education among the participants can be regarded as relatively high, with almost half of them having earned a standard or advanced degree.

As Table 15.1 shows, the average age of the 82 individuals who could be assessed over the 10-year interval was 75.2 years at T3, with $50 \%$ of these participants belonging to the younger age group (65-74 years old) and 50\% to the higher age group (75 years old or older). Women and men were almost equally represented in the sample (48 \% and $52 \%$, respectively). Most of the participants were married (66 $\%)$ and living in multiperson households (68\%). Approximately one in four (24\%) had lost their spouse. Satisfaction with their financial situation decreased on average from $M=7.7$ in 1995 to $M=7.0$ in 2005. Similarly, albeit at a lower level, subjective health was rated less positively 5 and 10 years after the first assessment $(M=6.9$ and 6.7 , respectively, compared to $M=7.3$ in 1995).

\section{Instruments}

In order to guarantee the comparability of the answers from all assessments, each follow-up retained main aspects of the instruments used in the first wave of data collection, that is, the standardized Outdoor Mobility Survey 1995 and the semistructured interview guidelines for the in-depth 1996 interviews (Mollenkopf et al., 2003, 2004a). Both of the instruments included questions on objective factors as well as subjective ratings concerning important prerequisites for mobility such as health and socioeconomic status (individual factors), social networks, and the physical environment (environmental factors). The survey questionnaire was partially based on methods used in previous studies, such as the Finnish Evergreen project (Heikkinen, 1998), the Nordic Research on Ageing (NORA) study (Avlund, Kreiner, \& Schultz-Larsen, 1993; Heikkinen, Berg, Schroll, Steen, \& Viidik, 1997), and the German Welfare Survey (Zapf \& Habich, 1996). Satisfaction with mobility, with the ability and opportunity to pursue leisure and other important life activities, and with

\footnotetext{
${ }^{1}$ Odds Ratio is a way to quantify how strongly the presence of a variable A increases or reduces the risk that another variable B is present or absent. Risk is calibrated in this analysis such that 1.0 means no change in the risk of B appearing when A is present. An OR of .94* means in our case that being younger significantly reduced the risk that a participant in our study would drop out. * $=$ significant at the .05 level; $* *=$ significant at the .10 level (tentatively significant).
} 
Table 15.1 Older adults' out-of-home mobility in two German cities: Description of the sample $(N=82)$

\begin{tabular}{|c|c|c|c|c|c|c|}
\hline \multirow[b]{2}{*}{ Characteristics } & \multicolumn{6}{|c|}{ Year } \\
\hline & \multicolumn{2}{|c|}{1995} & \multicolumn{2}{|c|}{2000} & \multicolumn{2}{|c|}{2005} \\
\hline \multirow[t]{3}{*}{ Mean age (years) } & \multirow{2}{*}{\multicolumn{2}{|c|}{62.2}} & \multicolumn{2}{|c|}{-} & \multicolumn{2}{|c|}{75.2} \\
\hline & & & \multicolumn{4}{|c|}{ Size of household } \\
\hline & $n$ & $\%$ & $n$ & $\%$ & $n$ & $\%$ \\
\hline Living alone & 13 & 15.9 & 19 & 23.2 & 26 & 31.7 \\
\hline \multirow[t]{3}{*}{ Living with others } & 69 & 84.1 & 63 & 76.8 & 56 & 68.3 \\
\hline & \multicolumn{6}{|c|}{ Marital status ${ }^{\mathrm{a}}$} \\
\hline & $n$ & $\%$ & $n$ & $\%$ & $n$ & $\%$ \\
\hline Married, living with a partner & 66 & 80.5 & 61 & 74.4 & 54 & 65.9 \\
\hline \multirow[t]{9}{*}{ Widowed } & 8 & 9.8 & 13 & 15.9 & 20 & 24.4 \\
\hline & \multicolumn{6}{|c|}{ Satisfaction with the financial situation of the household ${ }^{\mathrm{b}}$} \\
\hline & $M$ & $S D$ & $M$ & $S D$ & $M$ & $S D$ \\
\hline & 7.7 & 1.8 & 7.6 & 2.0 & 7.0 & 2.4 \\
\hline & \multicolumn{6}{|c|}{ Satisfaction with health ${ }^{\mathrm{b}}$} \\
\hline & $M$ & $S D$ & $M$ & $S D$ & $M$ & $S D$ \\
\hline & 7.3 & 2.1 & 6.9 & 2.4 & 6.7 & 2.5 \\
\hline & \multicolumn{6}{|c|}{ Changes in health } \\
\hline & $n$ & $\%$ & $n$ & $\%$ & $n$ & $\%$ \\
\hline Became better & & & 6 & 7.3 & 3 & 3.6 \\
\hline Became worse & & & 35 & 42.7 & 45 & 54.9 \\
\hline Remained the same & & & 41 & 50.0 & 34 & 41.5 \\
\hline
\end{tabular}

aThe analyses also included the characteristics married, living separately $(n=1)$, divorced $(n=3)$,

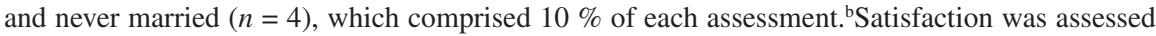
on an 11-point scale ranging from 0 (lowest satisfaction) to 10 (highest satisfaction)

Design by authors

life in general was assessed on an 11-point Likert-type scale ranging from 0 (lowest satisfaction) to 10 (highest satisfaction) (see Veenhoven, 1996; Zapf \& Habich, 1996), which was also used in the German Welfare Survey and the German SocioEconomic Panel (SOEP).

The focus of the semistructured interview, representing the qualitative part of the assessment, was on the aging adults' personal experiences and the subjective meanings they attributed to their out-of-home mobility options. In the second and third wave of assessment, additional questions were posed concerning changes between 1995 and 2000 and between 2000 and 2005 with respect to factors possibly affecting mobility.

\section{Data Analyses}

All interviews of the third assessment were tape recorded. After transcription of the qualitative portions of the interviews, content analysis (Mayring, 2003) was used to extract the main aspects and to group them into conceptually meaningful categories. 
The statements quoted in the results section represent especially characteristic and meaningful examples from the extensive amount of material. All names were changed to comply with data protection acts.

Quantitative data records were analyzed using the SAS statistical package (SAS Institute, Inc.), and the analysis was kept simple because of the rather small sample size. Statistical testing consisted mostly of t-tests and chi-square tests, with the usual levels of $p<.05^{*}$ applying.

In this study we focus particularly on finding ways to combine quantitative and qualitative data so that each data-analytic component complements the other.

\section{Results}

\section{Overview}

We start with findings addressing the subjective meaning of mobility over time, followed by perceived changes in mobility and perceived reasons for change. We then report on trajectories of satisfaction with key areas of outdoor mobility as well as the course of satisfaction with life in general. Finally, we explore the interindividual variability over time based on case analyses selected to underscore some of the extremes inherent in the data. Results presented in the first step are completely qualitative, whereas quantitative and qualitative data analyses are interwoven in the remaining steps.

\section{Subjective Meaning of Out-of-Home Mobility Over Time}

The terms in which our participants in 2005 expressed what out-of-home mobility meant to them were nearly the same as those they had used 10 years earlier (see Table 15.2). As in our earlier studies (Mollenkopf \& Flaschenträger, 2001; Mollenkopf et al., 2004a), we were able to categorize the elicited semantic material into seven categories: out-of-home mobility as a basic emotional experience; physical movement as a basic human need; mobility as movement and participation in the natural environment; mobility as a social need; mobility as an expression of personal autonomy and freedom; mobility as a source of stimulation and diversion; and mobility as a reflective expression of one's life force. For most of the respondents, mobility included more than one aspect, and some of the various facets are tightly interwoven, reflecting the multidimensional meaning of mobility. Taken all together, it seems that out-of-home mobility has maintained more or less the same bandwidth and richness of meaning over the 10-year observational period. 
Table 15.2 The meaning of out-of-home mobility: Main categories in sample verbal citations

\begin{tabular}{|c|c|}
\hline Year & Category \\
\hline \multicolumn{2}{|r|}{$\begin{array}{c}\text { The overarching meaning of mobility as a basic emotional experience, as essential for the } \\
\text { quality of life or for life itself }\end{array}$} \\
\hline 1995 & "Joy!”; "It's everything, it's life!" \\
\hline \multirow[t]{3}{*}{2005} & "A part of quality of life-yes, that's a really considerable part of quality of life!" \\
\hline & $\begin{array}{l}\text { "Really, it's getting out that makes up life, isn't it? When you stay at home you can } \\
\text { watch TV, but that's not life, that's dying slowly." }\end{array}$ \\
\hline & Physical movement as a basic human need \\
\hline 1995 & "A person has to move! I want to move and feel good when I do." \\
\hline \multirow[t]{2}{*}{2005} & $\begin{array}{l}\text { "Moving about outdoors is very important for me. I use every opportunity to get out } \\
\text { into the open air." }\end{array}$ \\
\hline & Mobility as movement and participation in the natural environment \\
\hline 1995 & "I have to get out, have to know what is going on in nature!" \\
\hline \multirow[t]{2}{*}{2005} & $\begin{array}{l}\text { "That's worth a lot....Of course, getting out, open air, movement, and other } \\
\text { environments and other people and nature-all this has to be worth a lot to everybody." }\end{array}$ \\
\hline & Moving around as a social need, as a desire for social integration and participation \\
\hline 1995 & "Still being able to take part in social life." "So that I don't get lonely." \\
\hline \multirow[t]{2}{*}{2005} & $\begin{array}{l}\text { "Getting out of one's home-this means meeting friends and acquaintances, socializing, } \\
\text { participating in culture, broadening one's horizons, and a lot more." }\end{array}$ \\
\hline & The possibility to move about as an expression of personal autonomy and freedom \\
\hline 1995 & "Being able to go out any time I want!" "Not being locked in!" \\
\hline \multirow[t]{2}{*}{2005} & $\begin{array}{l}\text { "A wonderful step to freedom....It has always been like this, the desire to go out into the } \\
\text { open and the ability to do so--that's simply beautiful. Being able to do so is important, } \\
\text { very important." }\end{array}$ \\
\hline & Mobility as a source of stimulation and diversion \\
\hline 1995 & $\begin{array}{l}\text { "Sometimes seeing something other than the four walls you live in!"; "So that I don't } \\
\text { go crazy up here!" }\end{array}$ \\
\hline 2005 & $\begin{array}{l}\text { "This means a great deal to me. Freedom of movement - and you have to see what's } \\
\text { new, the celebrations, meet other people and enjoy things a bit - that's what you need in } \\
\text { old age." }\end{array}$ \\
\hline \multicolumn{2}{|r|}{$\begin{array}{l}\text { The ability to move about as a reflective expression of one's remaining life force-A typical } \\
\text { topic of old age }\end{array}$} \\
\hline 1995 & "The last bit of freedom!" "Proof that I'm still a human being like anyone else." \\
\hline 2005 & $\begin{array}{l}\text { "This I can say: I'm still well-I am happy that I am still able to go out and move about } \\
\text { on my own." }\end{array}$ \\
\hline
\end{tabular}

Design by authors

\section{Perceived Changes in Out-of-Home Mobility Over Time and Perceived Reasons for Such Change}

Comparing the older adults' subjectively perceived changes in their out-of-home mobility over the 10-year interval gives a clear picture of continuity and change in this domain: About two thirds of the study's participants said in both follow-up assessments (2000 and 2005) that their mobility had not changed (Table 15.3). About one third (27\% in 2000 and $34 \%$ in 2005) reported a decline each time. 
Table 15.3 Perceived changes in out-of-home mobility: Two German cities

\begin{tabular}{|c|c|c|c|c|c|c|c|c|}
\hline \multirow[b]{2}{*}{ Change } & \multicolumn{8}{|c|}{ Year } \\
\hline & \multicolumn{4}{|c|}{2000} & \multicolumn{4}{|c|}{2005} \\
\hline & \multicolumn{8}{|c|}{ Total sample $(N=82)$} \\
\hline & \multicolumn{2}{|c|}{$n$} & \multicolumn{2}{|c|}{$\%$} & \multicolumn{2}{|c|}{$n$} & \multicolumn{2}{|c|}{$\%$} \\
\hline Better & \multicolumn{2}{|c|}{3} & \multicolumn{2}{|c|}{3.7} & \multicolumn{2}{|c|}{0} & \multicolumn{2}{|c|}{0.0} \\
\hline Worse & \multicolumn{2}{|c|}{22} & \multicolumn{2}{|c|}{26.8} & \multicolumn{2}{|c|}{28} & \multicolumn{2}{|c|}{34.2} \\
\hline \multirow[t]{4}{*}{ The same } & & & & & & & & \\
\hline & \multicolumn{8}{|c|}{ Age group (in years) } \\
\hline & \multicolumn{2}{|c|}{$\begin{array}{l}65-74 \\
(n=41)\end{array}$} & \multicolumn{2}{|c|}{$\begin{array}{c}75 \text { and older } \\
\quad(n=41)\end{array}$} & \multicolumn{2}{|c|}{$\begin{array}{c}65-74 \\
(n=41)\end{array}$} & \multicolumn{2}{|c|}{$\begin{array}{c}75 \text { and older } \\
(n=41)\end{array}$} \\
\hline & $n$ & $\%$ & $n$ & $\%$ & $n$ & $\%$ & $n$ & $\%$ \\
\hline Better & 3 & 7.3 & 0 & 0.0 & 0 & 0.0 & 0 & 0.0 \\
\hline Worse & 10 & 24.4 & 12 & 29.3 & 8 & 19.5 & 20 & 48.8 \\
\hline \multirow[t]{4}{*}{ The same } & 28 & 68.3 & 29 & 70.7 & 33 & 80.5 & 21 & 51.2 \\
\hline & \multicolumn{8}{|c|}{ Gender } \\
\hline & \multicolumn{2}{|c|}{$\begin{array}{l}\text { Female } \\
(n=39)\end{array}$} & \multicolumn{2}{|c|}{$\begin{array}{c}\text { Male } \\
(n=43)\end{array}$} & \multicolumn{2}{|c|}{$\begin{array}{l}\text { Female } \\
(n=39)\end{array}$} & \multicolumn{2}{|c|}{$\begin{array}{c}\text { Male } \\
(n=43)\end{array}$} \\
\hline & $n$ & $\%$ & $n$ & $\%$ & $n$ & $\%$ & $n$ & $\%$ \\
\hline Better & 1 & 2.6 & 2 & 4.6 & 0 & 0.0 & 0 & 0.0 \\
\hline Worse & 11 & 28.2 & 11 & 25.6 & 14 & 35.9 & 14 & 32.6 \\
\hline The same & 27 & 69.2 & 30 & 69.8 & 25 & 64.1 & 29 & 67.4 \\
\hline
\end{tabular}

Design by authors

Whereas $4 \%$ of the participants still stated an improvement in mobility in 2000, no one in 2005 reported an improvement. When age is applied as the distinguishing factor, it becomes evident that mobility worsens mainly after the 75th year of life. Almost $30 \%$ of the older age group stated a decline in 2000 compared to just $24.4 \%$ of the younger age group. Five years later, the proportions differed even more starkly (50\% and $20 \%$, respectively). Men and women showed only minor differences in this regard.

The perceived reasons for change in mobility can be attributed to both personal and environmental circumstances and are centered mostly on the theme of loss and deterioration. Declining health, in particular, but also financial constraints; the necessity of caring for a family member; difficulties with using a bicycle, car, or public transport and with coping with traffic conditions in general; and barriers in the built environment tend to result in mobility restrictions. The following quotations illustrate how older people experience their declining mobility and what impacts it has on their daily life.

I can no longer move about in the open countryside the way I used to. Five years ago I still went fishing, but I can't any more. If I go to the river, I risk being alone. And if I were to pass out, maybe I wouldn't fall into the water, but I might lay there a long time. (Mr. Nolte, 88 years old) 
Despite the prosthesis I feel pain, and this restricts my walking. And when I come homenot in winter, but in the spring and summer-I have to undress, and my wife gives me a shower. (Mr. Walter, 86 years old)

I don't have a car anymore and have to go everywhere on foot. There are only public modes of transport like the tram. But I have no further options. I would have to ask my son to take me somewhere. (Mr. Ober, 77 years old)

Well, as I said, I can no longer use my bike and I need some help for heavy household tasks more often nowadays. (Mrs. Diffler, 68 years old)

Of course, my whole situation has changed because of this task [caring for her husband, who suffers from dementia]. I myself, if I were independent, if I did not have to care for someone, I could walk, I could travel, and I could do anything I want. (Mrs. Hansen, 75 years old)

\section{Satisfaction with Key Areas of Mobility and Satisfaction with Life in General Over Time}

\section{Out-of-Home Mobility}

The appraisal of one's possibilities for mobility-assessed on an 11-point scale ranging from 0 (not satisfied at all) to 10 (very satisfied)-included all means of getting where one wants to go, either on foot, by bicycle, by car as a driver or passenger, or by public transport. In general, the older adults' satisfaction with their mobility options over the 10-year interval was high (Table 15.4). Toward the third assessment, however, it decreased from an average rating of $M=8.4$ (T1) to $M=8.3$ (T2) and $M=7.8$ (T3). This tendency was true of male participants in particular. Men and women aged 75 years or older also expressed less satisfaction with their mobility options than did younger elders (65-74 years old). As expected, older adults who reported a decline in their mobility options in the second and/or third assessment were significantly less satisfied with their mobility in general than people whose mobility had not changed.

\section{Public Transport}

Average satisfaction with public transport increased over the 10-year interval among the people who used it $(M=7.2$ in 1995 to $M=8.1$ in 2000 and $M=8.2$ in 2005; see Table 15.5). Women were less satisfied than men in all assessments. When respondents with mobility impairments were distinguished from respondents without such limitations, satisfaction of the impaired decreased only slightly between the second and third assessment (from $M=7.9-7.2$ ). Older adults who had not reported mobility restrictions showed a remarkable increase in their appraisal of public transport. 
Table 15.4 Satisfaction with mobility possibilities: Two German cities

\begin{tabular}{|c|c|c|c|c|c|c|}
\hline \multirow{3}{*}{ Characteristics of the sample } & \multicolumn{6}{|c|}{ Year } \\
\hline & \multicolumn{2}{|c|}{1995} & \multicolumn{2}{|c|}{2000} & \multicolumn{2}{|c|}{2005} \\
\hline & $M$ & $S D$ & $M$ & $S D$ & $M$ & $S D$ \\
\hline \multirow[t]{2}{*}{$N=82$} & 8.4 & 1.9 & 8.3 & 1.9 & 7.8 & 2.1 \\
\hline & \multicolumn{6}{|c|}{ Age group (in years) } \\
\hline $65-74(n=41)$ & 8.3 & 2.0 & 8.4 & 2.0 & 8.2 & 1.8 \\
\hline \multirow[t]{2}{*}{75 and older $(n=41)$} & 8.5 & 1.8 & 8.1 & 1.9 & 7.4 & $2.3^{\mathrm{b}}$ \\
\hline & \multicolumn{6}{|c|}{ Gender } \\
\hline Female $(n=39)$ & 7.9 & 2.1 & 7.8 & 2.4 & 7.6 & 2.5 \\
\hline \multirow[t]{2}{*}{ Male $(n=43)$} & 8.8 & 1.6 & 8.7 & 1.4 & 8.0 & $1.8^{\mathrm{b}}$ \\
\hline & \multicolumn{6}{|c|}{ Perceived changes in mobility 2005} \\
\hline Became worse $(n=28)$ & 8.6 & 1.6 & 7.8 & $2.3^{\mathrm{a}}$ & 5.8 & $2.4^{\mathrm{b}}$ \\
\hline Remained the same $(n=54)$ & 8.3 & 2.1 & 8.5 & 1.7 & 8.7 & 1.2 \\
\hline
\end{tabular}

Note. Satisfaction was assessed on an 11-point scale ranging from 0 (not satisfied at all) to 10 (very satisfied)

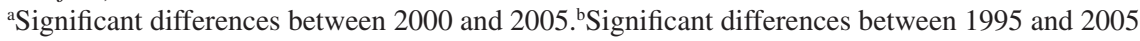
Design by authors

Table 15.5 Satisfaction with public transportation in two German cities

\begin{tabular}{|c|c|c|c|c|c|c|}
\hline \multirow{3}{*}{ Characteristics of the sample } & \multicolumn{6}{|c|}{ Year } \\
\hline & \multicolumn{2}{|c|}{1995} & \multicolumn{2}{|c|}{2000} & \multicolumn{2}{|c|}{2005} \\
\hline & $M$ & $S D$ & $M$ & $S D$ & $M$ & $S D$ \\
\hline \multirow[t]{2}{*}{$n=53$ (users only) } & 7.2 & 2.8 & 8.1 & 1.7 & 8.2 & $1.7^{\mathrm{b}}$ \\
\hline & \multicolumn{6}{|c|}{ Age group (in years) } \\
\hline $65-74(n=28)$ & 7.2 & 3.0 & 8.3 & 1.9 & 8.1 & 1.7 \\
\hline \multirow[t]{2}{*}{75 and older $(n=25)$} & 7.3 & 2.5 & 7.8 & 1.4 & 8.3 & 1.7 \\
\hline & \multicolumn{6}{|c|}{ Gender } \\
\hline Female $(n=27)$ & 6. & 2.8 & 7.8 & 2.0 & 8.0 & 1.9 \\
\hline \multirow[t]{2}{*}{ Male $(n=26)$} & 7.7 & 2.7 & 8.3 & 1.3 & 8.4 & 1.4 \\
\hline & \multicolumn{6}{|c|}{ Perceived changes in mobility 2005} \\
\hline Became worse $(n=14)$ & 7.9 & 1.9 & 7.9 & 1.6 & 7.2 & 2.3 \\
\hline Remained the same $(n=39)$ & 7.0 & $3.0^{\mathrm{a}}$ & 8.1 & 1.7 & 8.5 & $1.3^{\mathrm{c}}$ \\
\hline
\end{tabular}

Note. Satisfaction was assessed on an 11-point scale ranging from 0 (not satisfied at all) to 10 (very satisfied)

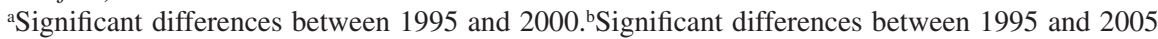
Design by authors

\section{Out-of-Home Leisure Activities and Travel}

Just as everyday activities require at least a minimum of physical mobility, so do leisure activities and travel. Hence, it is no surprise that changes in these domains eventually occurred most in people who reported mobility restrictions (61\% in both domains compared to $33 \%$ change in leisure and $49 \%$ change in travel among the nonimpaired). The main reasons for decreasing activities were the same as for 
Table 15.6 Satisfaction with possibilities of pursuing out-of-home leisure activities: Two German cities

\begin{tabular}{lcccccc}
\hline \multirow{2}{*}{ Characteristics of the sample } & \multicolumn{7}{c}{ Year } \\
\cline { 2 - 8 }$N=82$ & $M$ & $S D$ & $M$ & $S D$ & $M$ & $S D$ \\
& 8.1 & 2.0 & 7.9 & 2.4 & 7.5 & 2.3 \\
65-74 $(n=41)$ & \multicolumn{7}{c}{ Age group (in years) } \\
75 and older $(\mathrm{n}=41)$ & 8.0 & 2.0 & 7.7 & 2.7 & 7.8 & 2.1 \\
& 8.2 & 2.1 & 8.0 & $2.1^{\text {a }}$ & 7.1 & $2.5^{\text {b }}$ \\
Female $(n=39)$ & \multicolumn{7}{c}{ Gender } \\
Male $(n=43)$ & 8.1 & 2.0 & 7.6 & 2.7 & 7.6 & 2.3 \\
& 8.1 & 2.0 & 8.1 & 2.1 & 7.4 & 2.4 \\
Became worse $(n=28)$ & 8.1 & 2.1 & 7.4 & 2.7 & 6.3 & $2.5^{\text {b }}$ \\
Remained the same $(n=54)$ & 8.1 & 2.0 & 8.1 & 2.2 & 8.0 & 2.1 \\
\hline
\end{tabular}

Note. Satisfaction was assessed on an 11-point scale ranging from 0 (not satisfied at all) to 10 (very satisfied)

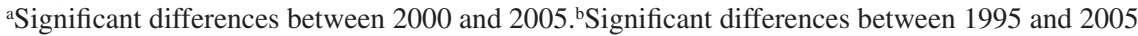

Design by authors

decreasing mobility: declining health, lack of money, the necessity of caring for a family member, the absence of a companion, difficulties with using transport modes, and environmental barriers.

About a quarter of all respondents and about half of the respondents with mobility impairments do not travel at all. This means, however, that half of older adults with impairments still travel, albeit to less distant destinations and for a shorter period than previously.

With regard to satisfaction with one's opportunities to pursue leisure activities and travel, the evident tendency was similar to that pertaining to satisfaction with mobility options. On average, and by subgroups, there was a significant decrease within the 10-year interval. Satisfaction with leisure activities decreased from $M=$ 8.1 in 1995 to $M=7.9$ in 2000 and $M=7.5$ in 2005 (Table 15.6). The figures for satisfaction with travel were $M=8.5$ (1995), $M=7.9$ (2000), and $M=7.0$ (2005) (see Table 15.7). The drops occurred mainly between the second and third assessment and among people who reported impaired mobility.

\section{Life in General}

The diverging individual developments in older adults' mobility and the respective impact on domain-specific satisfaction can be examined further in terms of satisfaction with life in general (Table 15.8). In the course of the follow-up investigations, overall satisfaction with life remained almost the same among the older adults who participated in all three assessments. On average it was rated $M=8.2$ in 1995, $M=8.2$ in 2000, and $M=8.0$ in the year 2005. The slight decrease toward the third 
Table 15.7 Satisfaction with possibilities for travel: Two German cities

\begin{tabular}{|c|c|c|c|c|c|c|}
\hline \multirow{3}{*}{ Characteristics of the sample } & \multicolumn{6}{|c|}{ Year } \\
\hline & \multicolumn{2}{|c|}{1995} & \multicolumn{2}{|c|}{2000} & \multicolumn{2}{|c|}{2005} \\
\hline & $M$ & $S D$ & $M$ & $S D$ & $M$ & $S D$ \\
\hline \multirow[t]{2}{*}{$N=82$} & 8.5 & 2.0 & 7.9 & $2.7^{\mathrm{b}}$ & 7.0 & $2.8^{\mathrm{c}}$ \\
\hline & \multicolumn{6}{|c|}{ Age group (in years) } \\
\hline $65-74(n=41)$ & 8.1 & 2.3 & 8.2 & $2.4^{\mathrm{b}}$ & 7.1 & $2.6^{\mathrm{c}}$ \\
\hline \multirow[t]{2}{*}{75 and older $(n=41)$} & 8.8 & $1.6^{\mathrm{a}}$ & 7.5 & 3.0 & 6.8 & $3.1^{\mathrm{c}}$ \\
\hline & \multicolumn{6}{|c|}{ Gender } \\
\hline Female $(n=39)$ & 8.3 & 2.2 & 7.6 & 3.1 & 6.9 & $3.0^{\mathrm{c}}$ \\
\hline \multirow[t]{2}{*}{ Male $(n=43)$} & 8.7 & 2.0 & 8.1 & $2.3^{\mathrm{b}}$ & 7.0 & $2.7^{\mathrm{c}}$ \\
\hline & \multicolumn{6}{|c|}{ Perceived changes in mobility 2005} \\
\hline Became worse $(n=28)$ & 8.5 & 2.6 & 7.3 & 3.1 & 6.7 & 2.5 \\
\hline Remained the same $(n=54)$ & 8.5 & 1.7 & 8.1 & $2.5^{\mathrm{b}}$ & 7.0 & $2.9^{\mathrm{c}}$ \\
\hline
\end{tabular}

Note. Satisfaction was assessed on an 11-point scale ranging from 0 (not satisfied at all) to 10 (very satisfied)

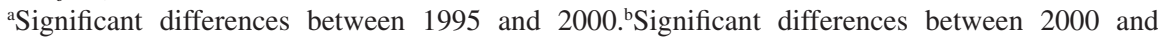
2005.'Significant differences between 1995 and 2005

Design by authors

Table 15.8 Satisfaction with life in general: Two German cities

\begin{tabular}{|c|c|c|c|c|c|c|}
\hline \multirow{3}{*}{ Characteristics of the sample } & \multicolumn{6}{|c|}{ Year } \\
\hline & \multicolumn{2}{|c|}{1995} & \multicolumn{2}{|c|}{2000} & \multicolumn{2}{|c|}{2005} \\
\hline & $M$ & $S D$ & $M$ & $S D$ & $M$ & $S D$ \\
\hline \multirow[t]{2}{*}{ Sample $(N=82)$} & 8.2 & 1.6 & 8.2 & 1.5 & 8.0 & 1.8 \\
\hline & \multicolumn{6}{|c|}{ Age group (in years) } \\
\hline $65-74(n=41)$ & 8.0 & 1.5 & 8.2 & 1.3 & 8.1 & 1.8 \\
\hline \multirow[t]{2}{*}{75 and older $(n=41)$} & 8.3 & 1.7 & 8.1 & 1.6 & 8.0 & 1.8 \\
\hline & \multicolumn{6}{|c|}{ Gender } \\
\hline Female $(n=39)$ & 7.9 & 1.7 & 8.1 & 1.6 & 7.8 & 2.0 \\
\hline \multirow[t]{2}{*}{ Male $(n=43)$} & 8.5 & 1.4 & 8.2 & 1.3 & 8.2 & 1.6 \\
\hline & \multicolumn{6}{|c|}{ Perceived changes in mobility 2005} \\
\hline Became worse $(n=28)$ & 8.6 & $1.7^{\mathrm{a}}$ & 7.5 & 1.7 & 7.1 & $1.9^{\mathrm{b}}$ \\
\hline Remained the same $(n=54)$ & 7.9 & 1.5 & 8.5 & 1.2 & 8.5 & 1.5 \\
\hline
\end{tabular}

Note. Satisfaction was assessed on an 11-point scale ranging from 0 (not satisfied at all) to 10 (very satisfied)

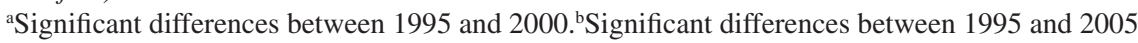

Design by authors

assessment point is not statistically significant. Women were somewhat less satisfied than men in all assessments, but again the decrease in satisfaction did not reach statistical significance. There was almost no difference between the younger and older age groups. However, when individuals with and without mobility impairments were distinguished, differences that support the notion of a close relationship between mobility and quality of life became obvious. Whereas satisfaction of older 
adults without mobility limitations even increased over time (1995: $M=7.9 ; 2000$ : $M=8.5 ; 2005: M=8.5$ ), life satisfaction of mobility-impaired individuals dropped significantly between both the first and second assessment and over the 10-year interval (1995: $M=8.6 ; 2000: M=7.5 ; 2005: M=7.1)$.

\section{Exploration of Interindividual Variability Over Time in a Case Contrast Approach}

In this section we again examine the key areas of out-of-home mobility from the above perspective and contrast selected extreme cases in their divergent trajectories. We use the total sample as a platform for overall comparison and provide background material and quotations, and figures to improve understanding of this diversity. In addition, Fig. 15.1 provides an illustration of interindividual differences in mobility as people age.

In comparison with changes in satisfaction of the total sample, the changes in satisfaction of Mr. Lechner (80 years old) and Mrs. Dahlmann (87 years old) mirror characteristic developments over the 10-year interval (Fig. 15.1, panel a). Mr. Lechner's satisfaction with his out-of-home mobility options had decreased between the years $1995(M=10.0)$ and $2000(M=9.0)$ because of a severe illness. He recovered between the second and the third assessment and was happy about his new freedom: "Thanks to my recovery it is possible to put more strain on my body, and I make the most of it for trips, hiking, and long-distance trips."

Together with his wife he walks at least five to six kilometers every day and does all his shopping and errands on foot or by public transport because they have no car available. He is still able to actively pursue his hobbies-cooking, painting, and forming wood and other materials - and because he experiences no impairments he said, "Hence, I can be quite satisfied" $(M=9.0)$.

The course that Mrs. Dahlmann's satisfaction took was quite different. Her mobility-related satisfaction had increased between $1995(M=7.0)$ and $2000(M=$ 9.00). However, she suffered from late effects of a cancer surgery and had to undergo operations on her veins and hip joint between the second and third assessment. Because the latter surgery was not completely successful, her mobility is severely restricted. She can still reach shops and services in the neighborhood on foot. However, longer trips are no longer possible: She gave up driving and is not yet accustomed to using public transport.

Inside activities are only a little limited —of course, my range is not large and that makes a big difference. But outdoor mobility and out-of-home activities are restricted....Actually, because of pain I walk with the aid of a cane anyway, and I feel extremely unsure as a result....The movability of my feet has decreased, and when I step down a curb or something similar I have to pay careful attention....In the past I loved hiking, even in high mountain areas-but this is no longer possible. My activities are limited to what I have to do: shopping and what is necessary for daily living. 


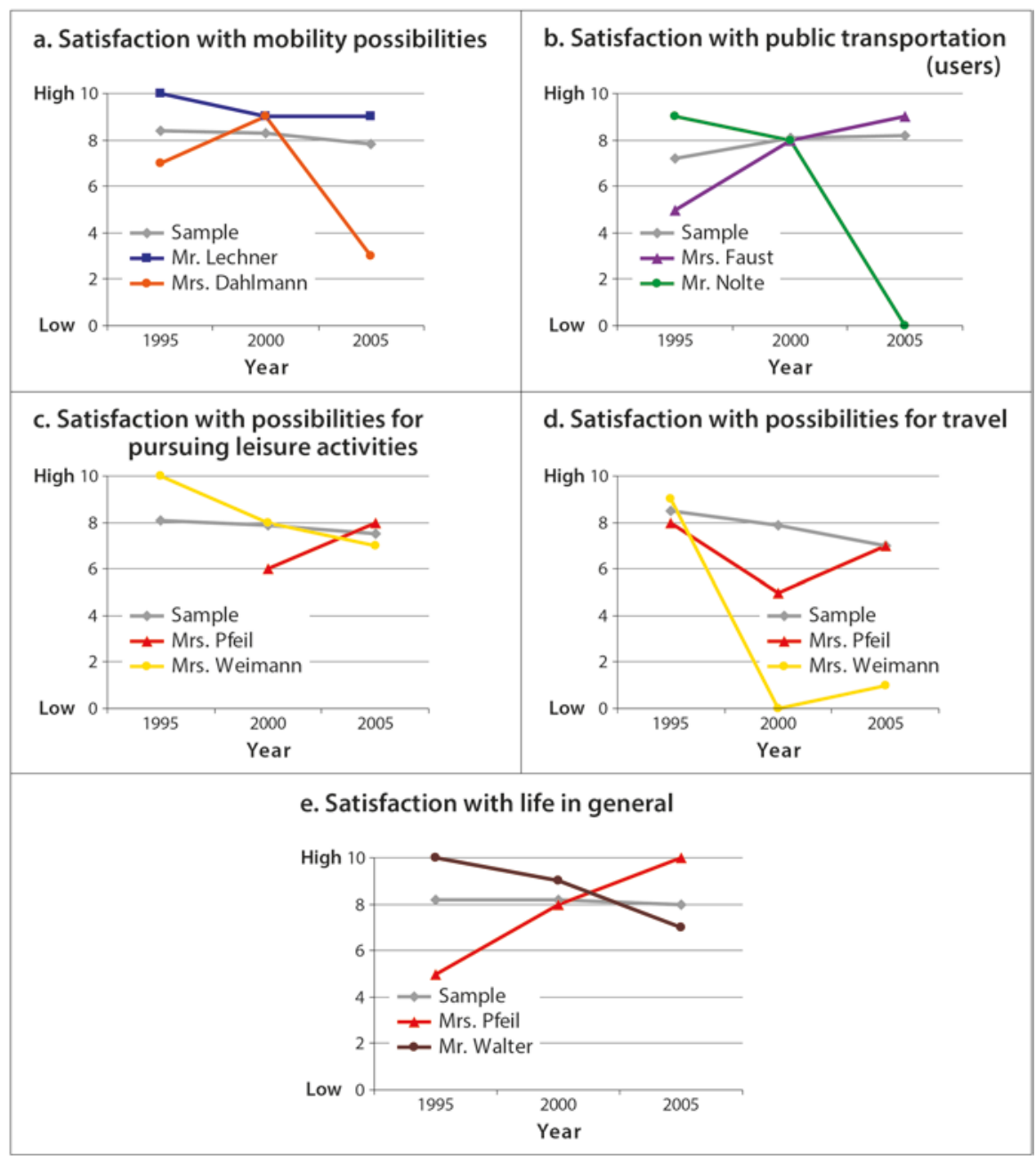

Fig. 15.1 Case examples to illustrate inter-individual differences in intra-individual changes in mobility-related indicators and general life satisfaction (Note: Satisfaction was assessed on an 11-point scale ranging from 0 (not satisfied at all) to 10 (very satisfied). Design by authors)

Against this background, Mrs. Dahlmann's satisfaction with her possibilities of moving about decreased sharply in the third measurement $(M=3.0)$. Together, the two examples point to large individual differences behind the general tendencies (Fig. 15.1).

The diverging individual conditions and experiences and the resulting evaluations regarding satisfaction with public transportation are again underscored with two examples (Fig. 15.1, panel b). Mrs. Faust, 77 years old, has taken daily care of her husband, who has been living in a nursing home. Her limited possibilities of moving about were reflected by a rather low satisfaction with public transport 
(1995: $M=5.0$ ). When her husband passed away between the second and third assessment, she was able to recover from this difficult life event mainly by pursuing out-of-home activities. Because she never obtained a driver's license, she has taken most of her trips on foot or by public transport. Because of her severe visual impairment, she has difficulties orientating herself when moving about on foot. For several years now public transport modes have therefore grown in significance to her because they allow her to maintain her activities (2000: $M=8.0 ; 2005: M=9.0$ ). "Everything by bus or tram," she said. "Except to the baker's. I walk there because of my visual impairment and-well, indeed, you are no longer entirely agile with advancing age."

Mr. Nolte is 88 years old and seriously impaired in his physical mobility. Nonetheless, in the first and second assessments he was still quite satisfied with public transport (1995: $M=9.0 ; 2000: M=8.0$ ). However, between the second and third assessment, his state of health worsened to the extent that he has depended ever since on help to be able to leave the house, so his satisfaction dropped to zero $(M=0.0)$. He complained:

My problem is that I no longer have the strength to walk to the tram stop by myself... because I am physically handicapped. I am no longer satisfied with the tram because I cannot use it anymore!

Satisfaction with one's possibilities for travel decreased significantly over time even among nonimpaired elders, whereas satisfaction with leisure opportunities stayed almost the same in the respective intervals. There were again great individual differences, however, as seen in the examples of Mrs. Pfeil and Mrs. Weimann (Fig. 15.1, panels $\mathrm{c}$ and $\mathrm{d}$ ).

The options for leisure activities and travel for 72-year-old Mrs. Pfeil had improved substantially in the last several years before the third assessment, not because of her health but because of changes in her social network. Caring for her almost 100-year-old mother required a great deal of time and energy and made other activities almost impossible. The situation changed when her mother passed away in 2002. "Since retiring..., I often take short trips, short cultural trips. Longer travel was not possible as long as my mother was living. I always went to see her. This has improved a lot now." Mrs. Pfeil was able to slowly resume her previous hobbies and traveling.

Well, I occupy myself with my computer, with my video recorder. I have been doing this for some time and have built up a little video library. I read-there just isn't time enough! I listen to music, actually everything beautiful....I watch TV, especially cultural programs.... Moreover, I visit the museum. In fact, outside the home I exercise, bowl, attend the theater and concerts, major events such as the one in the park recently.

Her wide range of activities contributes substantially to both her satisfaction with possibilities of pursuing outdoor leisure activities (2000: $M=6.0 ; 2005: M=8.0$ ) and travel (2000: $M=5.0 ; 2005: M=7.0)$.

Mrs. Weimann, 85 years old, is experiencing quite the opposite. Her husband's stroke has so severely restricted his mobility and reactions that she has to support 
him in almost all his activities of daily living. This situation heavily impacts her own and shared activities.

Leisure-I am rather satisfied in this regard....I still can go out with the dog; and at home, of course, I can do cooking, baking, gardening. Elsewhere, I play golf and bridge-but the latter is more in winter.... What is hard is that I can no longer play golf with my husband, that we can no longer take bicycle tours together, and that we cannot go on holiday anymore....I cannot take him with me. Even if he had a wheelchair, he would not be able to move around.

Consequently, her satisfaction with leisure activities, which had the highest rating $(M=10)$ in 1995 , fell to $M=8.0$ in 2000 and to $M=7.0$ in 2005. Regarding satisfaction with travel, the decline was even worse (1995: $M=9.0 ; 2000$ : 0.0; 2005: 1.0).

With respect to individual differences in general life satisfaction (Fig. 15.1, panel e), we refer again to Mrs. Pfeil, whose satisfaction with outdoor activities and travel rose remarkably when she no longer needed to care for her mother, a task that had prevented her from pursuing desired activities. The same holds true for her satisfaction with life in general. Starting from a very low rating $(M=5.0)$ in the first assessment in 1995, her subjective quality of life also increased when her radius of action widened again (2000: $M=8.0 ; 2005: M=10$ ).

Well, as long as I worried about my mother-I mean, even though she was very old she was still my mother. You are so worried, it was like a cloud hovering over you. We watched her decline for four years, and we did a lot of grieving. Meanwhile, I have gotten over it and can say, "This has changed." And this burden—it is a burden, whether you want to admit it or not-this has changed.

Hence, the positive changes in Mrs. Pfeil's out-of-home options and her related domain-specific satisfaction and subjective quality of life are due to changes in her social commitments.

By comparison, the example of 86-year-old Mr. Walter represents those men and women whose satisfaction with life in general decreased with advancing age, particularly because of health and mobility impairments. Although Mr. Walter was completely satisfied with his life in the first assessment $(M=10)$ and almost equally satisfied 5 years later $(M=9.0)$, this appraisal decreased in the third assessment $(M$ $=7.0$ ), although he did not suffer from severe impairments. Instead, he reported a general decline that most aging people have to cope with: "Because movability has diminished and sensitivity to pain has increased-thus we are somewhat less satisfied, I would say."

At the same time he is an example of the strength and adaptability older people develop in order to meet everyday hardships and to maintain satisfying activities despite mobility restrictions. "But yes, we struggle through, there is no whining and sniveling.... When the weather is reasonable we sit outside in the garden, and mostly we are four to five more people; that's fun." 


\section{Discussion}

The longitudinal investigation of aging adults' out-of-home mobility, carried out in two German cities over an observation interval of 10 years, provided the opportunity to assess and describe how individual, social, and environmental changes affect older men's and women's options of moving about and what effect these changes have on their satisfaction in different mobility-related domains.

One initial key finding is that out-of-home mobility-the opportunity and ability to move about outside one's home and get to places one wants or needs to gokeeps its remarkable significance as one grows older. Individual statements and the correlation between mobility and subjective evaluations indicate the manifold meanings of out-of-home mobility and, in particular, its positive quality. The meanings include aspects as basic as zest for life, autonomy and freedom, the sense of belonging, and just the pleasure of moving. These results are in line with findings reported in previous research (Banister \& Bowling, 2004; Coughlin, 2001; Fernández-Ballesteros et al., 2001; Holland et al., 2005; Mollenkopf et al., 2006), demonstrating that being able to go out, be active, and meet other people can result in positive feelings. Consequently, we agree with Banister and Bowling (2004), whose view on older people's travel and quality-of-life issues is wider than that conventionally found in transport research.

The results of the follow-up assessments also correspond with the welldocumented risk of declining health and movability with advancing age (Fozard \& Gordon-Salant, 2001; Heikkinen et al., 1997; Ketcham \& Stelmach, 2001; Spirduso, 1995), conditions that lead to decreasing out-of-home mobility (CERTU, 2001; Marottoli et al., 2000; OECD, 2001; O'Neill \& Dobbs, 2004). Study participants reported decreasing mobility and activities in all related domains. The decline in mobility finds expression in the older adults' subjective evaluation of their possibilities of getting out and about. In general, their satisfaction with possibilities for general mobility and with their opportunities to pursue leisure activities and travel over the 10-year interval is high, albeit with substantial individual differences. Moreover, subjective evaluations decreased in the total group among the persons aged 75 years or older, and in particular among individuals with mobility impairments in the third assessment. Women showed slightly lower satisfaction scores than men with respect to most of the domain-specific aspects of mobility, perhaps because of the fact that, among the present generations of older people, basic preconditions of mobility are generally more favorable for the "young" old and for men (e.g., Banister \& Bowling, 2004; ECMT, 2000; Rosenbloom, 2004; Siren \& Hakamies-Blomqvist, 2004). However, the general decline of out-of-home mobility over the 10-year interval was similar.

The development of satisfaction with public transport differs from this general pattern-it increases among all subgroups except for the users whose mobility had become worse between the second and third assessment. This positive appraisal can be explained in part by real improvements in the local transport systems of the cities under study. Moreover, if the nearest stop is within easy reach, the vehicles are 
easily accessible, and the connections are reliable and cheap, the public modes of transportation can be used as an alternative once previously used modes such as driving a car are no longer possible.

Apart from health decrements, environmental circumstances, including technological deterrents, taxing traffic conditions, and obligations such as caring for a family member, were found to interfere severely with the older adults' options of venturing out. The effect of such restrictions actually extends over all activities outside the home, so it is no surprise that mobility limitations affected the respondents' subjective quality of life as well. Although average life satisfaction of the total group remained almost the same over the 10-year interval, individuals whose mobility had worsened over time were not only markedly less satisfied than their nonimpaired contemporaries with their possibilities of being mobile and active but were also less satisfied with life in general. Together with the differential courses of domain-specific satisfaction among individuals whose venturing out was limited due to family obligations, these findings suggest a strong relationship between outof-home mobility and overall life satisfaction. They also support our view that older adults' quality of life is largely affected by mobility aspects that promote selfdetermination, flexibility, and the freedom to get where one wants and to do what one wants to do.

The results of our previous European studies (Mollenkopf et al., 2005, 2006) back up this supposition. The most important variable in almost all domain-specific appraisals and satisfaction with life in general was the ability to move about. Moreover, participation in a great diversity of outdoor activities and/or the satisfaction with one's opportunities to move about and pursue desired activities contributed substantially to both satisfaction with life in general and emotional well-being. Similarly, English studies found that poor morale became increasingly prevalent among older individuals with worsening mobility (Holland et al., 2005).

In addition, the findings can partly qualify the so-called satisfaction paradox, according to which high adaptability of older individuals allows them to maintain a high level of well-being despite unfavorable or aggravating life conditions (Staudinger, 2000). Obviously, such adaptability no longer has this effect if fundamental needs such as the need to be mobile and active are concerned. Means and average numbers are apt to obscure remarkable individual developments and related evaluations. Hence, only a differentiated view that considers the various conditions of older adults' living circumstances allows for valid statements about their out-of-home mobility. In this respect, the longitudinal perspective of our study and its combination of qualitative and quantitative methods proved particularly useful.

In terms of limitations of this study, it should be stressed that the individuals who were still able and willing to participate in this research after 10 years are a positive selection. Another limitation of this study is that we cannot distinguish the extent to which the findings are attributable to regional conditions. Studies comparing regional differences (e.g., Holland et al., 2005; Mollenkopf et al., 2005, 2006) suggest that a range of mobility factors play an equally important role in older adults' quality of life under diverging national and regional conditions. At the same time some mobility components showed differential significance depending on the area 
under observation. This observation points to the necessity of considering regional peculiarities as well as individual aspects in order to fully understand the respective relation between mobility options and quality of life.

The findings confirm what is known from our basic environmental gerontology approach (Wahl \& Oswald, 2010; Wahl et al., 2007), that an older individual's physical, social, and technical resources, as well as the structural resources provided by a region or locality, constitute basic prerequisites for moving about. The strong impact that the ability to pursue fulfilling activities has on the satisfaction with life reflects the importance that a congruence between personal and environmental resources has for an individual's well-being. At the same time, the respective circumstances seem to be mediated by the subjective evaluation of one's own possibilities and prevailing environmental conditions.

We believe that our findings have relevance for policy measures and further research alike. On the one hand, more detailed knowledge is necessary to improve the understanding of the nature, meaning, and significance of specific aspects of out-of-home mobility for older adults' quality of life. In this respect, compiling sociological, behavioral, and transportation approaches could provide further insights. On the other hand, the available data already show how crucial it is to promote the mobility of older adults as a means of enabling them to take part in meaningful activities at locations outside their homes through various structural, technological, and social measures of prevention and support in order to maintain their quality of life and well-being.

Acknowledgment We thank the Eugen-Otto-Butz Foundation, Germany (www.butz-stiftung. de), which was kind enough to provide the funding for the second follow-up in 2005 and, hence, the long-term perspective of this study.

\section{References}

Alsnih, R., \& Hensher, D. A. (2003). The mobility and accessibility expectations of seniors in an ageing population. Transportation Research, Part A: Policy and Practice, 37, 903-916. doi:10.1016/S0965-8564(03)00073-9

Avlund, K., Kreiner, S., \& Schultz-Larsen, K. (1993). Construct validation and the Rasch model: Functional ability of healthy elderly people. Scandinavian Journal of Public Health, 21, 233 246. doi:10.1177/140349489302100403

Banister, D., \& Bowling, A. (2004). Quality of life for the elderly: The transport dimension. Transport Policy, 11, 105-115. doi:10.1016/S0967-070X(03)00052-0

Centre d'études sur les réseaux, les transports, l'urbanisme et les constructions publiques [CERTU] (2001). La mobilité des personnes âgées-Analyse des enquêtes ménages déplacements [Mobility of older adults: Analysis of survey of household mobility]. Lyon: Rapport d'étude.

Clarke, A. J., \& Sawyers, K. M. (Eds.). (2004). Transportation in an aging society: A decade of experience. Transportation Research Board (TRB) Conference Proceedings: Vol. 27. Washington, DC: TRB.

Cobb, R. W., \& Coughlin, J. F. (2004). Transportation policy for an aging society: Keeping older Americans on the move. In A. J. Clarke \& K. M. Sawyers (Eds.), Transportation in an aging society: A decade of experience (pp. 275-289). Transportation Research Board (TRB) Conference Proceedings: Vol. 27. Washington, DC: TRB. 
Coughlin, J. (2001). Transportation and older persons: Perceptions and preferences. Washington, DC: Public Policy Institute. Retrieved from http://assets.aarp.org/rgcenter/i1/2001_05_transport.pdf

Cvitkovich, Y., \& Wister, A. (2001). The importance of transportation and prioritization of environmental needs to sustain well-being among older adults. Environment and Behavior, 33, 809-829. doi:10.1177/00139160121973250

European Conference of Ministers of Transport [ECMT]. (2000). Transport and aging of the population: Report of the 112th round table on transport economics, Paris, 19-20 November 1998. Paris: OECD.

Farquhar, M. (1995). Elderly people's definitions of quality of life. Social Science \& Medicine, 41, 1439-1446. http://dx.doi.org/10.1016/0277-9536(95)00117-P

Fernández-Ballesteros, R., Zamarrón, M. D., \& Ruíz, M. A. (2001). The contribution of sociodemographic and psychosocial factors to life satisfaction. Ageing and Society, 21, 25-43. doi:10.1017/S0144686X01008078

Fozard, J. L. (2003). Enabling environments for physical aging: A balance of preventive and compensatory interventions. In K. W. Schaie, H.-W. Wahl, M. Mollenkopf, \& F. Oswald (Eds.), Aging independently: Living arrangements and mobility (pp. 31-45). New York: Springer.

Fozard, J. L., \& Gordon-Salant, S. (2001). Sensory and perceptual changes with aging. In J. E. Birren \& K. W. Schaie (Eds.), Handbook of the psychology of aging (5th ed.) (pp. 31-45). San Diego: Academic Press.

Gabriel, Z., \& Bowling, A. (2004). Quality of life from the perspectives of older people. Ageing and Society, 24, 675-691. doi:10.1017/S0144686X03001582

Handy, S., Weston, L., \& Mokhtarian, P. L. (2005). Driving by choice or necessity? Transportation Research, Part A: Policy and Practice, 39, 183-203. doi:10.1016/j.tra.2004.09.002

Heikkinen, E. (1998). Background, design and methods of the Evergreen Project. Journal of Aging and Physical Activity, 6, 106-120.

Heikkinen, E., Berg, S., Schroll, M., Steen, B., \& Viidik, A. (Eds.). (1997). Functional status, health and aging: The Nora Study. Facts, research and interventions in geriatrics 1997. Paris: Serdi.

Heikkinen, E., Era, P., Jokela, J., Jylhä, M., Lyra, A., \& Pohjolainen, P. (1992). Socio-economic and life-style factors as modulators of health and functional capacity with age. In J. J. F. Schroots (Ed.), Ageing, health and competence (pp. 65-86). Amsterdam: Elsevier Science.

Hildebrand, E. D. (2003). Dimensions in elderly travel behaviour: A simplified activity-based model using lifestyle clusters. Transportation, 30, 285-306. doi:10.1023/A:1023949330747

Holland, C., Kellaher, L., Peace, S., Scharf, T., Breeze, E., Gow, J., \& Gilhooly, M. (2005). Getting out and about. In A. Walker (Ed.), Understanding quality of life in old age (pp. 49-63). Berkshire: Open University Press.

Ketcham, C. J., \& Stelmach, G. E. (2001). Age-related declines in motor control. In J. E. Birren \& K. W. Schaie (Eds.), Handbook of the psychology of aging (5th ed.) (pp. 313-348). San Diego: Academic Press.

Lash, S., \& Urry, J. (1994). Economies of signs and space. London: Sage.

Marottoli, R. A., Mendes de Leon, C. F., Glass, T. A., Williams, C. S., Cooney, L. M., \& Berkman, L. F. (2000). Consequences of driving cessation: Decreased out-of-home activity levels. Journal of Gerontology: Social Sciences, 55B, S334-S340. doi:10.1093/geronb/55.6.S334

Marottoli, R., Mendes de Leon, C. F., Glass, T. A., Williams, C. S., Cooney, L. M., Berkman, L., \& Tinetti, M. E. (1997). Driving cessation and increased depressive symptoms: Prospective evidence from the New Haven EPESE. Journal of the American Geriatrics Society, 45, 202206. doi:10.1111/j.1532-5415.1997.tb04508.x

Mayring, P. (2003). Qualitative Inhaltsanalyse. Grundlagen und Techniken [Qualitative content analysis: Principles and methods] (8th ed.). Weinheim: Beltz.

Mokhtarian, P. L. (2005). Travel as a desired end, not just a means. Transportation Research, Part A: Policy and Practice, 39, 93-96. doi:10.1016/j.tra.2004.09.005

Mollenkopf, H., \& Flaschenträger, P. (2001). Erhaltung von Mobilität im Alter [Maintaining mobility in old age]. Schriftenreihe des Bundesministeriums für Familie, Senioren, Frauen und Jugend: Vol. 197. Stuttgart: Kohlhammer. 
Mollenkopf, H., Baas, S., Kaspar, R., Oswald, F., \& Wahl, H.-W. (2006). Outdoor mobility in late life: Persons, environments and society. In H.-W. Wahl, H. Brenner, H. Mollenkopf, D. Rothenbacher, \& C. Rott, (Eds.), The many faces of health, competence and well-being in old age: Integrating epidemiological, psychological and social perspectives (pp. 33-45). Dordrecht: Springer.

Mollenkopf, H., Marcellini, F., Ruoppila, I., Baas, S., Ciarrocchi, S., Hirsiaho, N., Kohan, D., \& Principi, A. (2003). The MOBILATE follow-up study 1995-2000. Enhancing outdoor mobility in later life: Personal coping, environmental resources, and technical support. DZFA Research Report: Vol. 14. Heidelberg: German Centre for Research on Ageing [DZFA].

Mollenkopf, H., Marcellini, F., Ruoppila, I., Széman, Z., \& Tacken, M. (Eds.). (2005). Enhancing mobility in later life-Personal coping, environmental resources, and technical support. The out-of-home mobility of older adults in urban and rural regions of five European countries. Amsterdam: IOS Press.

Mollenkopf, H., Marcellini, F., Ruoppila, I., Széman, Z., Tacken, M., Kaspar, R., \& Wahl, H.-W. (2002). The role of driving in maintaining mobility in later life: A European view. Gerontechnology, 1, 231-250. doi:10.4017/gt.2002.01.04.003.00

Mollenkopf, H., Marcellini, F., Ruoppila, I., \& Tacken, M. (Eds.). (2004a). Ageing and outdoor mobility: A European study. Amsterdam: IOS Press.

Mollenkopf, H., Marcellini, F., Ruoppila, I., Széman, Z., Tacken, M., \& Wahl, H.-W. (2004b). Social and behavioral science perspectives on out-of-home mobility in later life: Findings from the European project MOBILATE. European Journal of Ageing, 1, 45-53. doi:10.1007/ s10433-004-0004-3

Mollenkopf, H., Ruoppila, I., \& Marcellini, F. (2007). Always on the go? Older people's outdoor mobility today and tomorrow: Findings from three European countries. In H.-W. Wahl, C. Tesch-Römer, \& A. Hoff (Eds.), New dynamics in old age: Individual, environmental and societal perspectives (pp. 175-198). Amityville: Baywood.

O’Neill, D., \& Dobbs, B. (2004). Age-related disease, mobility, and driving. In A. J. Clarke \& K. M. Sawyers (Eds.), Transportation in an aging society: A decade of experience (pp. 56-66). Transportation Research Board (TRB) Conference Proceedings: Vol. 27. Washington, DC: TRB.

Organization for Economic Co-operation and Development (OECD). (2001). Ageing and transport: Mobility needs and safety issues. Retrieved January 10, 2015, from http://www.ocs. polito.it/biblioteca/mobilita/OECDAgeing.pdf

Owsley, C. (2002). Driving mobility, older adults, and quality of life. Gerontechnology, 1, 220 230. doi:10.4017/gt.2002.01.04.002.00

Owsley, C. (2004). Driver capabilities. In A. J. Clarke \& K. M. Sawyers (Eds.), Transportation in an aging society: A decade of experience (pp. 44-55). Transportation Research Board (TRB) Conference Proceedings: Vol. 27. Washington, DC: TRB.

Pochet, P. (2003). Travel practices and access to the car among the elderly. Current developments and issues. Recherche Transport Sécurité, 79/80, 93-106. doi:10.1016/ S0761-8980(03)00009-8

Rammler, S. (2001). Mobilität in der Moderne. Geschichte und Theorie der Verkehrssoziologie [Mobility in modern society: History and theory of traffic sociology]. Berlin: edition sigma.

Rosenbloom, S. (2001). Sustainability and automobility among the elderly: An international assessment. Transportation, 28, 375-408. doi:10.1023/A:1011802707259

Rosenbloom, S. (2004). Mobility of the elderly: Good news and bad news. In A. J. Clarke \& K. M. Sawyers (Eds.), Transportation in an aging society: A decade of experience (pp. 3-21). Transportation Research Board (TRB) Conference Proceedings: Vol. 27. Washington, DC: TRB.

Schaie, K. W. (2003). Mobility for what? In K. W. Schaie, H.-W. Wahl, H. Mollenkopf, \& F. Oswald (Eds.), Aging independently: Living arrangements and mobility (pp. 18-27). New York: Springer.

Schaie, K. W., \& Pietrucha, M. (Eds.). (2000). Mobility and transportation in the elderly. New York: Springer. 
Schlag, B., \& Schade, J. (2007). Psychologie des Mobilitätsverhaltens [Psychology of mobility behavior]. Aus Politik und Zeitgeschichte, 29/30, 27-32. Retrieved from http://www.bpb.de/ system/files/pdf/0R4AHM.pdf

Siren, A., \& Hakamies-Blomqvist, L. (2004). Private car as the grand equaliser? Demographic factors and mobility in Finnish men and women aged 65+. Transportation Research Part F: Traffic Psychology and Behaviour, 7, 107-118. doi:10.1016/j.trf.2004.02.003

Spirduso, W. W. (1995). Physical dimensions of aging. Champaign: Human Kinetics.

Staudinger, U. M. (2000). Viele Gründe sprechen dagegen, und trotzdem geht es vielen Menschen gut: Das Paradox des subjektiven Wohlbefindens [There are many reasons against it, but many people still feel well: The paradox of subjective well-being]. Psychologische Rundschau, 51, 185-197. doi:10.1026//0033-3042.51.4.185

Transportation Research Board, National Research Council (1988). Transportation in an aging society: Improving mobility and safety for older persons [Special report 218]. Washington, DC: Transportation Research Board.

U.S. Department of Transportation (2003). Safe mobility for a maturing society: Challenges and opportunities. Washington, DC: U.S. Department of Transportation.

Veenhoven, R. (1996). Developments in satisfaction-research. Social Indicators Research, 37, 1-46. doi:10.1007/BF00300268

Wahl, H.-W., Mollenkopf, H., Oswald, F., \& Claus, C. (2007). Environmental aspects of quality of life in old age: Conceptual and empirical issues. In H. Mollenkopf \& A. Walker (Eds.), Quality of life in old age-International and multidisciplinary perspectives (pp. 101-122). Dordrecht: Springer.

Wahl, H.-W., \& Oswald, F. (2010). Environmental perspectives on aging. In D. Dannefer \& C. Phillipson (Eds.), International handbook of social gerontology (pp. 111-124). London: Sage.

Zapf, W., \& Habich, R. (Eds.). (1996). Wohlfahrtsentwicklung im vereinten Deutschland [Welfare development in the united Germany]. Berlin: edition sigma.

Open Access This chapter is distributed under the terms of the Creative Commons Attribution 4.0 International License (http://creativecommons.org/licenses/by/4.0/), which permits use, duplication, adaptation, distribution and reproduction in any medium or format, as long as you give appropriate credit to the original author(s) and the source, provide a link to the Creative Commons license and indicate if changes were made.

The images or other third party material in this chapter are included in the work's Creative Commons license, unless indicated otherwise in the credit line; if such material is not included in the work's Creative Commons license and the respective action is not permitted by statutory regulation, users will need to obtain permission from the license holder to duplicate, adapt or reproduce the material.

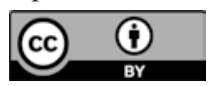

